\title{
The Sustainability of Social Science Survey Infrastructures
}

\author{
Tom Emery ${ }^{1}$
}

\begin{abstract}
Social science surveys are undergoing rapid change due to fundamental shifts in the way data is generated, collected and processed. In order to address this challenge, several large scale social surveys have been integrated into the European Strategic Forum for Research Infrastructures (ESFRI). This has allowed them to develop specialized and professionalized survey work flows within an integrated infrastructural context. This allows for greater sustainability through investment in survey methodologies and data collection which advance the field of social science. This paper examines three case studies within the ESFRI framework; The Survey of Health \& Retirement (SHARE) and the European Social Survey (ESS) are European Research Infrastructure Consortia and are both landmarks within the ESFRI landscape. The third case study is of the Generations \& Gender Programme which is an Emerging Community in the ESFRI landscape. The three case studies are used to illustrate the developments but also the persistent challenges for social surveys as they evolve with the framework of European Research Infrastructures. Each survey infrastructure is presented and it's scientific, financial and governance sustainability. Conclusions are drawn as to the sustainability of survey infrastructures and how they could be further improved.
\end{abstract}

\section{INTRODUCTION}

There are several patterns that are clearly discernible within society over the last twenty years. Societies and economies and more interconnected than ever before. This is not only due to technological change, but also to globalization more generally. The key societal challenges today are no longer national challenges but global ones. Climate change, environmental sustainability, international migration, trade relations, societal ageing, and labour automation are global challenges that require coordinated and cross-national responses.

These challenges also share a further feature in that they are the societal reaction to advances in science. Our capacity to shape our world has increased dramatically through our understanding of our changing climate, improvements in health and medicine, technological changes and greater systems integration. The science, in many ways, has delivered and the key challenges faced by national and international governance is how to deliver on the promise of science and react to the changes it brings about. To do so, a better understanding of our global society is needed [28].

Given this, there is a widely recognized need for high quality, cross-national social science infrastructures [8]. At the forefront of these infrastructures are social survey infrastructures. Social surveys are the most widely used data source

\footnotetext{
${ }^{1} \mathrm{~T}$. Emery is the Executive Director of the Open Data Infrastructure for Social Science \& Economic Innovations (ODISSEI) in the Netherlands and the Deputy Director of the Generations and Gender Programme emeryanidi.nI
}

for social scientists [11]. They are vital for understanding social change. They also support industry as innovations in survey methodologies help improve the quality of polls and commercial market research which are vital sources of information in modern industry.

In the last two decades social surveys have faced several existential problems. First, response rates to surveys have been falling steadily, leading to bias estimates and high nonresponse rates [24]. Second, due in part to high non-response rates, fieldwork costs have been increasingly dramatically and undermining the financial sustainability of survey infrastructures. Third, the increasing pervasiveness of mobile web devices has changed the primary channel of communication for many individuals. Such devices could theoretically help address these first two problems but their impact has been limited due to the impact of these technologies on survey methods and subsequent data quality [9][10].

Finally, social surveys have been faced with the changing nature of data within society more generally [22]. Specifically, survey infrastructures have had to adapt to meet the increases in the four V's that define a 'big data' society: velocity, veracity, variety and volume. To meet these challenges survey infrastructures have had to undergo a process of specialization and professionalization in the way they are structured and implemented [3].

Europe has a number of high quality and world leading international and national surveys. ESS, SHARE, the GGP, EVS and many others have provided insights into society and the way we live that would not have been possible any other way. They are vital for a better understanding of our changing society and ultimately better policy designs and implementation. ESS and SHARE are both ERIC's and have established themselves as ESFRI Landmarks. The GGP is an emerging community and is applying for ESFRI status in 2020.

ESFRI has provided a framework for infrastructures to develop but there is a great deal of flexibility in the governance and operational structure that infrastructures adopt. For social surveys, there are considerable variations in how data collection is incorporated within the research infrastructure itself. In this paper we explore the ways in which these three surveys have evolved within the European Research Infrastructure framework to address the aforementioned societal and technical challenges and achieve financial and methodological sustainability in a challenging climate. There are crucial differences in the approaches pursued by each infrastructure and these will be examined and their consequences discussed. 


\section{METHODOLOGY}

This paper seeks to compare the governance structures of the European Survey Infrastructures and the degree to which these governance structures are fit for purpose in delivering high quality science in an efficient and financially sustainable manner. Knowledge and research infrastructures have taken very different approaches to governance and organization. Both in terms of the degree of centralization and the degree of specialization of nodes, all affect the cultural and technical operations of the infrastructure [5].

To achieve this, three distinct survey infrastructures are examined in turn. Their governance structure is described, the implications for technical operations outlined and they are evaluated against three criteria which cover the breadth of data collection, the sustainability of data collection and the financial sustainability of the core operational activities.

1) The number of countries participating in the latest round of data collection.

2) The retention rate of countries between rounds of data collection, taken as the proportion of countries in a given round that fielded the survey in the subsequent round.

3) The financial sustainability of the infrastructure as measured by the proportion of core operational expenses of the infrastructure financed by the financial contributions of members.

These criteria were chosen to reflect three central functions of a cross-national survey infrastructure. First, a crossnational infrastructure is designed to increase the comparability of data and the scope for cross-national analysis. This is represented by the number of countries covered. This neglects the precise comparability of data and the value of the comparisons available, but is a good quantitative indicator of coverage for each survey infrastructure.

SHARE and GGP are longitudinal studies and the degree to which they are able to retain countries is vital for the design of their studies. Whilst ESS is not a longitudinal study, it does provide a repeated cross-sectional design which ensures that round of participation provides increasing returns to participation for countries. The ability to retain countries within the studies is therefore a critical indicator for sustainability.

The financial sustainability of the core operational activities represented by the exposure of the infrastructure to 'project money' or 'soft money' is a widely used indicator for the general financial sustainability of a research infrastructure. It goes beyond a basic assessment of a balance sheet analysis and differentiates financial resources based on whether they are associated with specific activities or whether they are for the financing of core activities. Such a differentiation is essential for moving beyond a simple budgetary perspective on infrastructure finances [2].

The data from this paper was collated from survey infrastructures within the Synergies in European Research Infrastructures in the Social Sciences project (SERISS, www.seriss.eu). This project has received funding from the
European Unions Horizon 2020 research and innovation programme under grant agreement No 654221. SERISS aims to increase cooperation between social survey infrastructures in Europe and develop common solutions to the challenges facing social surveys.

The primary focus of SERISS is on shared technical knowledge and infrastructure. The design and implementation of these shared technologies is however affected by the divergent governance and legal structures in place within the various survey infrastructures. The evidence drawn upon within this paper stems from a variety of public and nonpublic sources that were provided by the survey infrastructures.

- Annual reports and accounts reported by the ERIC Survey Infrastructures as part of their legal reporting requirements [12][26]. The Annual Report for 2019 for the GGP was also used [17].

- The statutes of the ERIC Survey Infrastructures and the Statutes and by-laws of the GGP [13][27].

- Reporting of cost structures by each infrastructure ahead of the SERISS Survey Expert Network Meeting in the Hague in May 2019.

- Expert interviews with individuals from within each survey infrastructure.

- Expert interviews with individuals from within the ESFRI structure were also conducted.

- The analysis also draws on an extensive literature review for the general operation of distributed research infrastructures.

The European Value Study was not included within the analysis as it does not aspire to be a centralized research infrastructure. The European Value Study is conducted every 9 years which entails a long and highly variable funding cycle that is not best serviced by a permanent research infrastructure. Given this, it was omitted from the analysis. Further information on the European Values Study can be found via its website; https://europeanvaluesstudy.eu/.

\section{THE EUROPEAN SOCIAL SURVEY}

\section{A. Background}

The European Social Survey (ESS) is a biennial repeated cross-sectional survey of European Countries [15]. This means that every two years, interviews are held with approximately 2,000 people in each participating country and for each round the survey is conducted, a new sample of people is chosen to interview (i.e. respondents are not interviewed more than once).

The interviews are conducted exclusively via a face to face meeting between the respondent and the interviewer and the interview can take up to an hour. The ESS has strict protocols for how these interviews are conducted to ensure that standards are uniform across countries.

The data collected by the ESS focuses primarily on attitudes and behaviours of Europeans [7]. A proportion of the questionnaire stays the same for every round of the ESS and there are two modules included in each round as the 
result of an open competition amongst European scientists. Within the competition, societal relevance and scientific quality are key evaluation parameters. Recent topics covered by the ESS include climate change, migration, democracy and intergenerational solidarity.

Once the data is collected from respondents it is made freely available to anybody after approximately a year. The ESS focuses on being as open access as possible and the data is available for download via the website (www.europeansocialsurvey.org). Because of the open access policy, the ESS is widely used in teaching and has been used by over 100,000 individuals.

\section{B. Governance}

The ESS-ERIC was established in November 2013 and is hosted by City University in the United Kingdom [13]. There are 23 member states which are signatories of the ERIC and Switzerland acts as an observer. Representatives of the member states sit on the ESS General Assembly. The General Assembly appoints the Director of the ESS, who leads the Core Scientific Team and convenes the National Coordinators Forum.

The Core Scientific Team consists of 29 representatives from 8 separate research institutions in 7 different countries. These representatives are responsible for the central coordination and implementation of the survey in a distributed, network organization [1]. This network structure is similar to a matrix organizational structure in so much as the activities of the infrastructure are defused across multiple institutions and several institutions operate across multiple domains of the infrastructures scientific work such as translation, sampling, archiving and communications [?].

The National Coordinators Forum consists of representatives from all countries currently participating in the European Social Survey. This includes the ERIC member countries but also participating countries who are not yet signatories to the ERIC. At the time of writing there were 28 countries represented in the National Coordinators Forum.

Under the statutes of the ESS-ERIC, the General Assembly approves the budget for the Core Scientific Team [13]. Each ERIC member is required to contribute to the budget at a level relative to their countries GDP. For 2016-17, this budget was $€ 2.4$ million. This covers the operations of the Core Scientific Team but does not include data collection costs within countries.

As host country, the United Kingdom contributes a significant proportion of this budget at approximately $€ 764,000$ per year. The remainder is provided through membership contributions by the other ERIC members. For 2016-17, the average contribution for the ERIC members (excluding the UK) was $€ 88,000$.

The cost of data collection is covered by national governments, as stipulated in the ESS-ERIC statutes but is paid directly and therefore incurs the cost of VAT. The statutes indicate that as an ESS ERIC member, each country must field the ESS every two years in compliance with the technical guidelines set out by ESS-ERIC. The monetary value of this data collection is not collected or recorded by ESS-ERIC central office. ESS-ERIC recently conducted a pilot of a centralized tendering framework in Austria that would allow for the VAT exemption of the ERIC to be applied to fieldwork, but the outcome of this pilot are as of yet not conclusive. Leveraging this tax advantage has been a key strategy in the development of many infrastructures [19]

Based on discussions with survey methodologists and experts in the field as well as individuals within the ESS, it is understood that the costs of fieldwork varies between $€ 200,000$ and $€ 800,000$ per round. The wide range in this figure is due to the highly variable fieldwork costs and conditions across participating countries. Using the midpoint of this range, it can therefore be estimated that the current costs of data collection for one round of the ESS are approximately $€ 15$ million. A $20 \%$ reduction in this via the VAT exemption would be a saving of $€ 3$ million per round

\section{Performance}

The ESS performs well against the first criteria of evaluation, the number of countries participating. In the latest round of the survey 30 countries are anticipated to participate and of the EU member states it is only Cyprus, Malta and Luxembourg which are absent.

It could be desirable for the ESS to consider methods and approaches to conduct the survey in small member states such as these. This could entail solidarity payments from richer member states or adapted fieldwork guidelines that allow for the smaller populations to be included.

The ESS performs well on the second criteria which is the degree to which it expand to additional countries wave on wave. Over the 9 rounds of the ESS, a country has fielded the survey having not fielded it in the previous round 33 times. However the ESS does find the retention of countries difficult. Over the 9 rounds, countries have failed to field the survey having done so in the previous round on 25 occasions.

From this we know that there has been a net increase of 8 countries between wave 1-9 but also that there has been significant instability in the fielding of the survey across countries. The retention rate (i.e. the number of countries from the previous round who collect data again in the current round) has fluctuated considerably. From rounds 2 to 3 the retention rate was $100 \%$. From round 1 to 2 it was just $77 \%$. Over the 9 rounds, the average retention rate has been $88 \%$.

Finally, the ESS performs well on the financial sustainability criteria. The ESS isolates the budget for its Core Scientific Team from those of externally financed projects. Therefore the expenses of the Core Scientific Team for 2016-2017 were $98 \%$ covered by the financial contributions of the ERIC [12]. This is therefore a very sustainable financial model. Furthermore this sustainability is guaranteed by the process by which the Core Scientific Teams budget is developed, agreed and financed. 


\begin{tabular}{lccc} 
& ESS & SHARE & GGP \\
\hline Host Country & UK & DE & NL \\
Legal Entity & ERIC & ERIC & Foundation \\
Initial source of financing & ESF & NIH & UNECE \\
Date data collection started & 2002 & 2004 & 2004 \\
Annual Core Operational Costs & $€ 2.4 \mathrm{mil}$ & $€ 2.8 \mathrm{mil}$ & $€ 857 \mathrm{k}$ \\
Estimated average Cost of fieldwork per country & $€ 500 \mathrm{k}$ & $€ 750 \mathrm{k}$ & $€ 450 \mathrm{k}$ \\
Countries participating & 30 & 28 & 20 \\
Percentage of operational budget financed structurally & $98 \%$ & $54 \%$ & $46 \%$ \\
Retention of countries between rounds & $88 \%$ & $93 \%$ & $78 \%$
\end{tabular}

TABLE I

OVERVIEW OF EUROPEAN SURVEY INFRASTRUCTURES [12][26][17]

\section{THE SURVEY OF HEALTH, AGEING \& RETIREMENT IN EUROPE}

\section{A. Background}

SHARE is a longitudinal study of Europeans aged over 50. It conducts biennial interviews with the same individuals and continues to do so until they either refuse to participate, are unable to participate, emigrate or die [6].

SHARE aims to study the financial and health situation of older adults as they age in order to better understand the ageing process and how it is shaped by socioeconomic contexts. SHARE started to collect data in 2004 and has since conducted 8 rounds of data collection with some individuals followed for 14 years.

SHARE has now completed over 400,000 interviews with individuals over 50. These interviews are comprehensive last for 75 minutes on average. They include a detailed overview of individuals finances including their assets and pension arrangements. They also include the collection of bio-markers and completion of health tests including blood spots, grip strength tests, walking tests, cognitive tests and psychological tests [6].

The data collected by SHARE is exceptionally powerful because it tracks the changes within individuals over time and this has led to a rapid and broad advance in our understanding of the ageing process and how it is shaped by an individuals personal circumstances. SHARE has over 9,000 users and more than 2,200 journal articles [26].

However, the strength of the SHARE design is also its primary vulnerability in that the design is highly reliant on continued data collection which is threatened by attrition at the individual or country level [4]. It is also a necessity that such data is collected face-to-face and therefore SHARE is unable to take advantage of the efficiencies offered by web based data collection. Face-to-face interviews are required because of health measures that are collected and low internet penetration amongst older populations targeted by SHARE.

\section{B. Governance}

SHARE-ERIC was the first ERIC established in March 2011. The initial ERIC consisted of just five countries but has since grown to 16 members at the time of writing [27]. The ERIC was initially hosted by the Netherlands but was transferred to Germany who continue to be the host of SHARE-ERIC.
The members of the SHARE-ERIC appoint representatives to the SHARE Council which is the equivalent to the General Assembly within the ESS. SHARE-ERIC members are required to make three types of financial contributions. First, there is the cost of fielding the survey in the country. This is detailed below. Second, each country must cover the costs of coordination in their host country. This item is regularly provided in-kind by member countries. The third item is a flat contribution of $€ 10,000$ from each ERIC member. The fourth item is what is referred to as 'column D' financing. This refers to a share of the common coordination costs which are not covered by the host country of other funding sources.

The Council elects the Managing Director of SHARE who leads the Management Board which consists of the International Coordinator, the Questionnaire Coordinator, the Area Coordinators and the Chair of the Assembly of Country Team Leaders.

The Management Board of SHARE-ERIC is primarily based at the Max-Planck-Institut für Sozialrecht und Sozialpolitik (MEA) in Munich. Professor Axel BörschSupan has been the Managing Director of SHARE-ERIC since its inception and the activities of the infrastructure are more centralized than in the ESS. SHARE's core operational activities are based in six instutes across six countries (Germany, the Netherlands, France, Denmark, Israel and Italy). The organization of the operational activities is hierarchical, specialized and coordinated by MEA [20].

The annual operational budget of the core scientific team in SHARE is $€ 2.8$ million of which $€ 1.5$ million (54\%) is spent at MEA in Germany [26]. The costs of the coordination based at MEA are covered by Federal Ministry for Research and Education (BMBF) and the Max Planck Society (MPG). The remaining coordination costs are covered by project funds and grants provided by the Directorate-General for Employment, Social Affairs and Inclusion of the European Commission.

The centralization of SHARE activities is evident in the data collection process. The SHARE-ERIC statutes oblige members to pay for data collection. However, unlike in ESS the data collection by survey agencies is managed by SHARE-ERIC itself. Once a country has become a signatory to SHARE-ERIC, the SHARE International Coordinator will conduct a tender process in coordination with the national 
coordinator. This is a centralized process and SHARE-ERIC ensures that all tenders are compliant with the SHARE fieldwork protocols and study design.

Once a tender process is completed and a fieldwork contractor identified, the SHARE-ERIC member is invoiced for the fieldwork costs. These funds are transferred to SHAREERIC who subsequently pays the fieldwork contractor. This allows SHARE-ERIC to maintain control and oversite over the tendering process and also to apply the VAT exemption that ERIC's enjoy. This can reduce fieldwork costs by approximately $20 \%$.

Fieldwork costs within SHARE are highly variable across countries but greater transparency exists than in the ESS due to centralized tendering. In the 7th wave of SHARE, fieldwork ranged from $€ 190,000$ in Latvia through to $€ 1.4$ million in Germany [26]. The average cost of fieldwork in the 7th wave was approximately $€ 750,000$ which gives an overall fieldwork cost of $€ 21$ million per wave assuming that 28 countries participate in data collection as was the case in wave 7 .

\section{Performance}

In wave 8 of SHARE, 28 countries were able to participate. The level of coverage is therefore very good. However, there are notable hurdles to wider coverage. Amongst the EU-28, three member states chose not to participate. These were Ireland, the Netherlands, and the United Kingdom. These are sizeable countries and their inclusion is unlikely in the foreseeable future.

In Ireland (TILDA) and the United Kingdom (ELSA), alternative ageing surveys are in place. Coordination between these surveys and SHARE is in place through the Gateway to Global Ageing Data. However, the coordination between these surveys is sub-optimal and undermines the rationale of a centralized European Survey on Ageing. In the Netherlands, the financing of SHARE was not provided and Article 9 of the SHARE-ERIC statutes which stipulate fieldwork must be financed have not been enforced. The failure to enforce this article creates a moral hazard as the project progresses as it is evident that the ERIC statutes are not enforceable.

On the second criteria, SHARE performs well on retaining countries. On only 7 occasions has a country failed to field a wave of SHARE having fielded the previous wave (Greece, Hungary, Ireland, Israel (twice), the Netherlands, Portugal and Poland). In contrast, over 8 rounds of data collection 25 countries have fielded the survey having not participated in the previous round.

The average retention rate of countries between rounds is $93 \%$. This was $100 \%$ between round 67 which is the latest round for which data is available and peaked at $15 \%$ between waves 3 and 4 when the financial crisis and retrenchment were at their peak. On this criteria, SHARE therefore performs well although maintaining a $100 \%$ retention rate is key to the studies design.

On the final criteria, SHARE illustrates a significant exposure to project financing. Just $58 \%$ of the coordination costs for SHARE are attributable to structural financing by ERIC members. Whilst ERIC members contribute significantly to fieldwork, contributions to the development of the infrastructure are very limited and the infrastructure relies on research grants from the National Institute of Health in the United States, the Research Funds of the Research Commission and grants from DG Employment to finance core scientific activities. As of February 2019, the SHARE Management Board have proposed a significant increase in membership contributions to cover the costs of central coordination [27].

SHARE is a successful and well financed project and has attracted diverse and significant financial contributions to its development. However, these funds are for time limited and for specific activities and do not secure a sustainable funding for the infrastructure [26]. If SHARE-ERIC required membership fee's comparable to those of ESS, a further $€ 1.4$ million would be secured in structural funding. This would allow for the acquired funding to be directed at survey innovations, methodological developments and panel retention.

\section{THE GENERATIONS \& GENDER PROGRAMME}

\section{A. Background}

The Generations and Gender Programme (GGP) is distinct from the ESS and SHARE. ESS and SHARE were created at the turn of the millenium and evolved alongside the European Research Area which was established in 2000. By contrast the GGP is a programme that has evolved out of the community of nations within the United Nations Economic Commission for Europe (UNECE) and in collaboration with the United Nations Population Fund [16].

In 1972 the United Nations Population Fund supported the development of the World Fertility Survey (WFS) which was a survey on fertility and family behaviour in both developed and developing economies. 20 developed countries in the UNECE region participated in this survey. The data collection was very diffuse and international coordination was limited.

In 1992 the UNECE coordinated the Fertility and Family Survey in 23 countries of the UNECE region [14]. This was similar in nature to the FFS but was more standardized and extensive in design. These studies were a considerable success and have proved vital in developing population policies.

In 2000 the UNECE coordinated a follow up to these studies which would be even more coordinated and ambitious in design and incorporated a longitudinal element for the first time. This became known as the GGP. This was fielded in 19 countries in 2004 with subsequent waves in 2007 and 2011 [29]. In 2009, the GGP sought to integrate with the European Research Area a design study for a European research infrastructure was financed. In 2016 was identified as an emerging community of the ESFRI roadmap.

In 2020 the GGP will be conducting a new round of data collection. This is will be a continuous longitudinal data collection with waves three years apart [16]. Interviews are to be conducted both face-to-face and online and each 
interview lasts approximately one hour. The GGP focuses on collecting data about family and life course dynamics as well as personal life histories. The data is comparable with the previous round of the GGP, the FFS and the WFS creating a comparable data record covering nearly 50 years.

A further contrast with the ESS and SHARE is that the GGP is a global rather than exclusively European infrastructure. In the previous round data was collected in Japan, Russia, Georgia, and Australia. In the new round data collection is planned in China, Kazakhstan, Taiwan, Japan, Canada, Argentina, Uruguay and Brazil which illustrates the broad geographic reach of the project [17].

\section{B. Governance}

Between 2009 and 2019, the GGP was governed by a Memorandum of Understanding between 16 research organizations in 12 European Countries. These included statistical offices, demographic research institutes, government agencies, and universities. These 16 organizations form the Consortium Board of the GGP. In 2019, the GGP created the GGP Foundation which is a Dutch Stichting. As such, the GGP is undergoing a process of professionalization, centralization and specialization commonly observed in knowledge and research infrastructure [21].

A Stichting is a foundation and recognized legal entity. The 16 members of the GGP Consortium Board contribute financially to the operation of the GGP and appoint the Director of the GGP. The GGP has been hosted by the Netherlands Interdisciplinary Demographic Institute (NIDI) in the Hague since 2009 and as such the Netherlands is the host country of the GGP.

The Director is responsible for the operation and management of the GGP and is supported by a central coordination team which is primarily based at NIDI [17]. There is additional support from INED in Paris and the Max Planck Demographic Research Institute in Rostock. The total costs of the GGP core scientific activities were $€ 857,641$ for 2018 .

The core scientific activities are financed by three separate sources. First, NIDI provides the largest contribution to operations as host. This amounts to approximately $€ 277,000$ per year. Second, Consortium Board members contribute in cash and in-kind approximately $€ 26,000$ per year on average. Together, these funds cover $46 \%$ of the core operational costs of the GGP. The remainder is financed through project money, grants and revenues from service provision.

Data collection in the GGP is financed by national funding agencies. The GGP does not receive or administer funds for fieldwork. However, the GGP does charge a coordination for the fieldwork each time it is conducted. In exchange for this fee, national coordinators receive a range of products and services that enable them to conduct high quality data collection that can be integrated in the GGP. The cost for this is $€ 20,000$ per country, per wave.

\section{Performance}

The evaluation of the GGP is problematic given that it is not currently in full operation and will not be until 2020 .
The evaluation criteria are therefore applied against the best available information. With regards to the first criteria, at the time of writing 29 countries intend to participate in the new round of data collection in 2020. However, there are a large number of European Member States which are currently not planning to participate.

Most notably, the countries of Southern Europe are absent from the studies design and this has significant consequences for the scientific value of the data collected. Therefore whilst the GGP has breadth comparable to the ESS and SHARE, significant efforts need to be made to increase the participation of these countries. To address this, the GGP is attempting to reduce fieldwork costs through online data collection but this strategy is still pending a final proof of concept in 2019 [17].

With regards to the second criteria, it is not possible to evaluate the GGP's retention of countries under its current governance structure. However, the retention rate in the previous round was just $78 \%$ between wave 1 and 2 and only $33 \%$ between wave 2 and 3 [16]. This was a clear illustration of the problems associated with a decentralized and informal governance structure. During the financial crisis, the retention of countries witin the GGP was particularly poor. Ahead of the new round of data collection the GGP needs to attain a retention rate of $80 \%-90 \%$ to be considered a success.

On the final criteria, the GGP also performs poorly relative to both SHARE and the ESS as just $46 \%$ of its core operational activities are financed through structural commitments of member organizations. This is to be expected as the GGP is less mature than the ESS and SHARE and is not underpinned by an ERIC structure. The GGP is currently in the process of implementing higher financial contributions from its members which will raise the proportion covered by structural funds to $75 \%$.

On these criteria it is clear that the GGP is not as developed as the ESFRI landmarks SHARE and ESS. Nevertheless, the comparison of an emerging community project with mature survey infrastructures provides a wider perspective for evaluating the sustainability of social science survey infrastructures.

\section{CONCLUSIONS}

Surveys all over the world struggle to achieve sustainable financing, particularly cross-national studies. This is problematic as cross-national, comparable data is particularly useful for understanding the way in which society shapes individuals lives and mutual learning between countries in how to address societal challenges [4][7].

The problem with financing of data collection in these surveys is that financing must be $100 \%$ available, $100 \%$ of the time. There is no room for error or flexibility. If a country is unable to participate in a round of data collection it undermines the survey infrastructure in two ways. Firstly, it interrupts the longitudinal nature of the survey and produces gaps in coverage for specific populations.

Increased attrition, gaps in the record and increased recall error all undermine the value of the survey data for a specific 
country. Even for cross-sectional studies like the ESS, a loss of coverage in a round has an impact on studies using a repeated cross-sectional design which are very useful for understanding social change.

Secondly, it reduces the number of countries that we compare, and this detracts from the analysis. For European Research Infrastructures this is particularly problematic as there is an incentive to have data from all member states so that the data can be used for pan-European analysis [26]. This has never been achieved by a European Research Infrastructure because there is no room for error. If just one of the 28-member states fail to field the survey, then it devalues the whole endeavor.

The analysis presented here has evaluated the sustainability of three survey infrastructures: ESS, SHARE and the GGP. In terms of the breadth of coverage, all three infrastructures perform well and have been expanding in recent years. Nevertheless the governance models appear to obstruct further expansion that would advance the development of the projects.

For ESS, the success of the ERIC membership has been clear with 23 members. However, smaller countries such as Luxembourg, Malta and Cyprus lie outside this model and the ESS should consider how such smaller countries could be incorporated as the value of a pan European survey is notable.

For SHARE, the centralized nature of the governance structure prevents the incorporation of large preexisting ageing studies in countries such as the UK, Ireland and Norway. The inclusion of these countries is not essential for the development of SHARE but it does potentially undermine the surveys position as covering all EU member states and usage in European level policy analysis.

The criteria used in the analysis revealed that both SHARE and ESS have some degree of sustainability issues. ESS has a relatively low retention rate, although this appears to be improving. However, it is very financially secure and sustainable.

In contrast, SHARE has a high retention rate but its financing is currently not sustainable. SHARE has been successful in attracting a diverse range of funders but this has been used to finance core scientific activities as opposed to development, innovation and expansion activities to which these funds should be dedicated.

The ESS has demonstrated that a membership fee is achievable and could provide greater financial flexibility for the infrastructure to support fieldwork in countries where there is a funding short fall or invest in innovations that reduce the fieldwork costs across the infrastructure. The SHARE-ERIC Management Board recently set out funding proposals along such lines [27].

For the GGP, it is clear that the infrastructure is in development and not as mature as the ESS or SHARE. To increase the retention of countries and the proportion of financing that is structural, the GGP should go further than establishing a Dutch Foundation and should aim to establish an ERIC.
The statutes of this ERIC should include membership fees that provide for the financial sustainability of the infrastructure, carry a clear obligation to collect data through multiple rounds of the survey and data collection costs that are transparent.

What is also apparent from the assessment of these infrastructures is a tendency towards centralization and specialization which is reflected financially as a transfer from all member states to institutes in the host country. These host countries are often richer, Western European countries (the United Kingdom, Germany and the Netherlands). For ERIC members who are from the less affluent parts of Europe with less developed knowledge infrastructures, this is an outsourcing of research activities that undermines national investments. This could be undermining the ability of infrastructures to secure long term commitments.

Furthermore, given the infrastructures are virtual in nature and inherently distributed, this tendency could be potentially unnecessary and counter productive. Whilst the value of standardization and compliance is clear within the survey process, it seems to be against the current trend for distributed and virtual infrastructures and the potential they bring about [25]. Developing national nodes, capacity and expertise in less affluent member states would increase capacity in these states, increase buy-in from national governments in these states and potentially reduce operational costs due to lower staff expenses and overheads.

Overall, European Survey Infrastructures have encountered problems with sustainability over the last decade. Amendments to the governance arrangements currently in place will help the survey infrastructures further strengthen and build on the considerable progress that has already been made. This iterative learning process is accelerated and improved when the survey infrastructures share experiences and information about the evolution of their governance models.

\section{ACKNOWLEDGMENT}

This paper was written as the conclusion of my field project within the Executive Masters in the Management of Research Infrastructures (EMMRI) at Bicocca University. EMMRI was developed by the Research Infrastructure Training Programme (RITrain). RITrain is an EU-funded Horizon 2020 project aimed at improving and professionalizing the training of managerial and leadership staff in research infrastructures (Project Number: 194491).

I would like to thank my colleagues and tutors at EMMRI who provided I highly stimulating and constructive environment in which to develop. I would particularly like to thank Enrico Guarini and Georges Dagher for supervising this fieldwork project. I would also like to thank Professor Anne Gauthier for enabling me to take part in this programme and supporting my work throughout.

Finally I would like to thank the social science survey community. In particular, Rory Fitzgerald, Sarah Butt, Lorna Ryan, Axel Börsch-Supan, Annette Scherpenzeel, and Ruud Luijkx. 


\section{REFERENCES}

[1] Antivachis, NA, Angelis, VA. Network organizations: The question of governance. Procedia Social and Behavioral Sciences, 2014; 175: 584-592.

[2] AQPC, Financial Planning and Analysis: Influencing Corporate Performance with Stellar Processes, People, and Technology, Houston, 2015

[3] Banks R, Laurie H. From PAPI to CAPI: the case of the British Household Panel Survey. Social Science Computer Review. 2000; 18(4): 397-406.

[4] Bergmann M, Kneip T, De Luca G, Scherpenzeel A. Survey participation in the survey of health, ageing and retirement in Europe (SHARE), Wave 1-6. Munich: Munich Center for the Economics of Aging. 2017.

[5] Borgman CL, Edwards PN, Jackson SJ, Chalmers MK, Bowker GC, Ribes D, Burton M, Calvert S. Knowledge infrastructures: Intellectual frameworks and research challenges, Ann Arbor, 2013

[6] Brsch-Supan A, Brandt M, Hunkler C, Kneip T, Korbmacher J, Malter F, Schaan B, Stuck S, Zuber S. Data resource profile: the Survey of Health, Ageing and Retirement in Europe (SHARE). International journal of epidemiology. 2013; 42(4): 992-1001.

[7] Breen MJ, editor. Values and Identities in Europe: Evidence from the European Social Survey. Taylor Francis; 2017.

[8] Connelly R, Playford CJ, Gayle V, Dibben C. The role of administrative data in the big data revolution in social science research. Social Science Research. 2016; 59:1-2.

[9] Cook C, Heath F, Thompson RL. A meta-analysis of response rates in web-or internet-based surveys. Educational and psychological measurement. 2000; 60(6): 821-36.

[10] Daikeler J, Silber H, Bosnjak M. Where do web surveys work? A meta-analysis of response rate experiments across countries. Research Synthesis 2018, Trier, 2018.

[11] Dua A, Nelle D, Stock G, Wagner GG. Facing the future: European research infrastructures for the humanities and social sciences. Berlin, 2010

[12] European Social Survey ERIC, Annual Activity Report 2016-2017, London, 2018. Available via www.europeansocialsurvey.org

[13] European Social Survey ERIC, Statutes of the European Social Survey European Research Infrastructure Consortium (ESS ERIC) (Version effective 1 August 2018), London, 2018

[14] Festy P, Prioux-Marchal F. An evaluation of the Fertility and Family Surveys project. United Nations Publications; 2002.

[15] Fitzgerald R, Jowell R. Measurement equivalence in comparative surveys: the European Social Survey (ESS)from design to implementation and beyond. Survey methods in multinational, multiregional, and multicultural contexts. 2010: 485-95.

[16] Gauthier AH, Cabao SL, Emery T. Generations and Gender Survey study profile. Longitudinal and Life Course Studies. 2018; 9(4): 45665.

[17] The Generations and Gender Programme, Annual Report 2018, The Hague, 2019. Available via www.ggp-i.

[18] Gottlieb, M. R. The matrix organization reloaded: adventures in team project management. London: Praeger. 2007

[19] Hilling A, Hallonsten O, Elgaard E, Kim K. Tax Policy Issues in Connection with the European Spallation Source Project and Other European Research Infrastructure Consortiums. SPO-Skattepolitisk Oversigt.2017; (8):279-90.

[20] Jain RK, Jain R, Triandis HC. Management of research and development organizations: managing the unmanageable. John Wiley \& Sons; 1997.

[21] Jansen D, editor. New forms of governance in research organizations: Disciplinary approaches, interfaces and integration. Springer Science \& Business Media; 2007.

[22] Kitchin R. The data revolution: Big data, open data, data infrastructures and their consequences. Sage; 2014.

[23] Meijer I, Molas-Gallart J, Mattsson P. Networked research infrastructures and their governance: the case of biobanking. Science and Public Policy. 2012; 39(4): 491-9.

[24] Meyer BD, Mok WK, Sullivan JX. Household surveys in crisis. Journal of Economic Perspectives. 2015; 29(4): 199-226.

[25] Reinicke B. Creating a Framework for Research on Virtual Organizations. Journal of Information Systems Applied Research. 2011; 4(1): 49

[26] SHARE-ERIC, Annual Activity Report 2017-2018, Munich, 2018. Available via www.share-project.org
[27] SHARE-ERIC, Statutes of the SHARE-ERIC Concerning the Building Up and Operation of the Survey of Health, Ageing and Retirement in Europe (SHARE) (Version effective 12 February 2019), Brussels, 2019

[28] Trivellato U. Microdata for social sciences and policy evaluation as a public good. InData-Driven Policy Impact Evaluation 2019 (pp. 27 45). Springer, Cham.

[29] Vikat A, Spder Z, Beets G, Billari F, Bhler C, Dsesquelles A, Fokkema T, Hoem JM, MacDonald A, Neyer G, Pailh A. Generations and Gender Survey (GGS): Towards a better understanding of relationships and processes in the life course. Demographic research. 2007; 17: 389440 